\title{
Menanamkan Spiritual Leadership di Era Milenial untuk Membangun Jiwa Kepemimpinan
}

\author{
Margaretha Taniria Sarumaha, Sariyatun, Susanto
}

Universitas Sebelas Maret

margarethataniria16@gmail.com

\section{Article History}

received $1 / 9 / 2021$

\begin{abstract}
This study aims to provide an effort in the Millennial Era in terms of leadership by instilling Spiritual Leadership values. This is because the millennial era is an agent of change and is also the spearhead of the leadership relay in building this nation's civilization. The approach used in this research is a library research approach. This approach is carried out by examining theories, concepts and principles related to the discussion. While data collection is done by document study techniques, namely data obtained from the relevant literature. The data were analyzed by qualitative descriptive analysis, in which all the collected data will be analyzed systematically. The results showed that Spiritual Leadership as a fundamental aspect of motivation from an action and behavior in the effectiveness of building a leadership spirit in the Millennial Era. Because, Spiritual Leadership contains exemplary, service, integrity, love, and divine values in goals, processes, culture and attitudes that are very much needed in the Millennial Era in responding to technological challenges.
\end{abstract}

Keywords: Spiritual Leadership, Millennial Era

\begin{abstract}
Abstrak
Penelitian ini bertujuan untuk memberikan suatu upaya di Era Milenial dalam hal kepemimpinan dengan menanamkan nilai-nilai Spiritual Leadership. Hal ini dikarenakan era milenial yang merupakan agent of change dan juga ujung tombak estafet kepemimpinan dalam membangun peradaban bangsa ini. Adapun pendekatan yang digunakan dalam penelitian ini ialah pendekatan kepustakaan (library research), pendekatan ini dilakukan dengan cara menelaah teori, konsep dan asas yang berkaitan dengan pembahasan. Sedangkan pengumpulan data dilakukan dengan teknik studi dokumen yaitu data yang diperoleh dari Kepustakaan yang relevan. Data dianalisis dengan analisis Deskriptif Kualitatif, yang mana keseluruhan data yang terkumpul akan dianalisis secara sistematis. Hasil penelitian menunjukkan bahwa Spiritual Leadership sebagai aspek mendasar motivasi dari suatu tindakan dan perilaku dalam kefektivan membangun jiwa kepemimpinan di Era Milenial. Karena, Spiritual Leadership mengandung keteladanan, pelayanan, integritas, kasih, serta nilai ke-Tuhanan dalam tujuan, proses, budaya dan sikap yang sangat dibutuhkan di Era Milenial dalam menjawab tantangan teknologi.
\end{abstract}

Kata kunci: Spiritual Leadership, Era Milenial

Social, Humanities, and Education Studies (SHEs): Conference Series https://jurnal.uns.ac.id/shes

p-ISSN 2620-9284

e-ISSN 2620-9292 
SHEs: Conference Series 5 (1) (2022) 309- 317

\section{PENDAHULUAN}

Generasi Milenial atau generasi $Y$ adalah istilah yang dicetuskan oleh William Strauss dan Neil Howe dalam beberapa buku yang ditulis, keduanya merupakan pakar sejarah dan penulis di Amerika. Lebih lanjut Strauss dan Neil dalam bukunya yang berjudul "Generations: The History of America's Future 1584-2026", diungkapkan bahwa generasi millenial merupakan generasi yang lahir di rentang tahun 1982-2000. Berdasarkan penelitian, Lancaster dan Stillman (2002) bahwa generasi milenial disimbolkan sebagai Generasi Y yang banyak menggunakan teknologi komunikasi.

Pandangan diatas diperkuat oleh Erkutlu (2011), generasi milenial merupakan generasi modern yang aktif bekerja untuk menyelidiki dan berpikir secara inovatif melalui penggunaan teknologi. Generasi millennial menghadapi tantangan di era globalisasi karena didukung oleh perkembangan teknologi yang semakin pesat. Era globalisasi tentu saja membawa dampak perubahan, baik positif maupun negatif dalam semua bidang kehidupan manusia.

Terjadinya perubahan ditengah kehidupan yang semakin cepat, maka dalam hal ini generasi milenial yang merupakan agen perubahan sekaligus penerus dalam memimpin untuk membangun peradaban. Oleh karena itu, diperlukan perubahan dalam struktural, proses perubahan besar. Maka, kepemimpinan model lama pun tidak akan cocok lagi dan diperlukan perbaikan serta dikembangkan. Karena pesatnya pertumbuhan generasi milenial di Indonesia, gaya kepemimpinan yang muncul harus menyesuaikan kecepatan dan polanya.

Generasi milenial yang saat ini banyak berpengaruh juga harus dipimpin dengan gaya kepemimpinan milenial. Menjadi pemimpin yang baik di generasi milenial saat ini dan masa depan adalah tantangan yang kritis. Banyak pendapat yang mengatakan bahwa kepemimpinan adalah karakter sejak lahir. Dahulu, ketika pemimpin dilahirkan sebagai raja, dapat dikatakan bahwa mereka yang memperoleh pengetahuan dan pengalaman kepemimpinan hanya berada di lingkungan nyata.

Saat ini kehidupan manusia telah memasuki era globalisasi yang menawarkan tawaran kemudahan untuk menerima segala aspek kehidupan. Proses ini tampak rumit dalam menangani masalah yang perlu ditangani dan diselesaikan. Kompleksitas yang muncul dari adanya masalah dapat mempengaruhi kualitas orang dalam dedikasi terhadap pekerjaan yang mereka lakukan atau lakukan. Oleh karena itu, mengenali suatu masalah membutuhkan sosok manusia yang memiliki jiwa kepemimpinan yang baik dan memiliki komitmen yang tinggi terhadap suatu organisasi. Karena pengaruh gaya kepemimpinan sendiri tidak hanya memiliki visi tentang kinerja karyawan atau bawahannya, tetapi dapat memberikan kepuasan kerja dan mendorong anggota organisasi untuk terlibat dalam organisasi mereka (Pratiwi, Widjaja dan Widayati, 2018).

Salah satu yang menjadi perhatian utama saat ini adalah adanya gaya kepemimpinan baru, yaitu kepemimpinan spiritual. Kepemimpinan spiritual adalah kemampuan seorang pemimpin untuk memberikan dorongan, semangat dan prinsipprinsip terhadap hasil kerja, baik di tempat kerja maupun di masyarakat (Fairholm, 1998:13). Sementara itu, Ashmos dan Duchon (2000) menemukan bahwa pola gerakan spiritualitas di tempat kerja terkait dengan tradisi nilai-nilai agama dan ini merupakan kesan yang umum di kalangan agama tetapi tidak umum di organisasi, dan administrasi klasik. Kepemimpinan spiritual adalah pembentukan nilai, sikap dan perilaku yang diperlukan untuk memotivasi diri sendiri dan orang lain untuk menciptakan rasa kesejahteraan spiritual (spiritual survival) melalui panggilan dan keanggotaan (Fry, 2003).

Mengutip pendadapat Agung (2009) bahwa spiritualitas dalam bekerja merupakan rangkaian keterkaitan antara Tuhan dengan manusia dalam aspek kehidupan hingga kemudian akan memiliki karakter jati diri. Kesetaraan dari Spiritualitas tidak termasuk dalam agama tertentu karena universal, karena, Spiritualitas memiliki 
hubungan langsung antara roh dan jiwa dengan Sang Pencipta. Agar tatanan spiritualitas dikorelasikan dengan prinsip-prinsip kepemimpinan, dimana terdapat nilai, sikap dan perilaku seseorang sehingga dapat memotivasi diri sendiri dan orang lain. Konsep gaya kepemimpinan memiliki peran tersendiri, di antaranya diungkapkan oleh Warilow (2009) yaitu kepemimpinan memiliki komponen indikator transformasi kepemimpinan, yang meliputi karisma, motivasi inspiratif, stimulasi intelektual dan perhatian pribadi.

Sementara diungkapkan oleh Mansyur (2013) bahwa dalam leadership style menggunakan teori Personal Prophetic Leadership (Prophec-L) sebagai contoh upaya mengatasi korupsi didasarkan pada dalam lima yakni pendekatan itrinsik (spiritual), yakni meliputi: 1) keyakinan; 2) bekerja dengan orientasi ibadah, 3) berjiwa humanisme, dan 5) memimpin berdasarkan kata hati. Pada penelitian ini menggunakan pendekatan gaya kepemimpinan melalui pendekatan spiritual. Pendekatan memimpin spiritualitas ini sebagai upaya pembentukan karakter kaum milenial yang muncul berdasarkan respon dalam menghadapi era modern yang lebih mengutamakan akal, empiris serta hal-hal yang bersifat materialistik, sekularistik, hedonistik dan transaksional.

Mengutip pendapat Nata dalam Jurnal Yusuf (2020) Kehidupan milenial mengantarkan manusia hingga tahapan, melakukan hal yang menakjubkan, seperti teknologi digital, kloning dan seterusnya. Akan tetapi karena, tidak dibarengi dengan landasan spiritual, agama serta moral yang hakikatnya terdapat hubungan intrinsik bersama Sang Pencipta terhadapt keseluruhan ciptaan manusia, generasi milenial dianggap lebih merujuk pada pencapaian pada hawa nafsu serta keinginan mengambil segala hal yang diinginkannya. Maka dari itu dalam penelitian ini bertujuan untuk membahas mengenai model kepemimpinan spiritual (spiritual leadership) di Era Milenial untuk Membangun Jiwa Kepemimpinan bagi kalangan insan milenial dalam pembentukan karakter diri menjadi seorang Pemimpin.

\section{Generasi Milenial}

\section{KAJIAN TEORI}

Berdasarkan pandangan para ahli bahwa generasi milenial biasanya menggunakan awal 1980-ansebagai awal kelahiran kelompok ini dan pertengahan tahun 1990-an hingga awal 2000-an sebagai akhir kelahirannya. Namun faktanya, generasi Milenial yang lahir dan hidup di era digital tidak asing dengan kemajuan teknologi yang terus berkembang di sekitar mereka. Berdasarkan artikel Millennial Trends (2016), menurut Yuswohady, generasi yang lahir di awal 1980-an hingga 2000-an dikenal sebagai generasi millennial. Menurut para ahli, tidak ada pengelompokan khusus dari generasi milenial, namun para ahli sosial mengutip buku mereka. Bukunya, Mix Marcom yang berjudul Millennials, yang mengungkapkannya dari segi karakter umum generasi milenial yang lahir pada tahun 1980-2000 (Mix Marcom, 2018).

Selain itu, Mix Marcom mengungkapkan bahwa ada 10 karakter yang termasuk dalam Generasi Milenial, yaitu: 1) pengalaman di bidang teknologi; 2) konsumtif; 3) menabung untuk sesuatu yang diinginkan; 4) berpengetahuan; 5) digital sebagai alat komunikasi; 6) menjadi pengusaha; 7) mengutamakan fasilitas dan penghargaan di tempat kerja; 8) Peningkatan pengalaman; 9) transparansi radikal; dan 10) takut tersesat/ fear of missing out (FOMO), (Mix Marcom, 2018). Pada generasi ini, manusia sering kali tidak bisa lepas dari keberadaan teknologi. Dunia sekarang ini, kepemimpinan didominasi oleh kaum milenial. Ternyata generasi milenial saat ini mendominasi posisi kepemimpinan dalam kehidupan sehari-hari. Tidak menutup kemungkinan, di 2025 akan menjadi banyak sektor di antaranya ada dari didominasi oleh generasi Milenial.

Generasi ini merupakan aset suatu negara karena di masa depan mereka akan menjadi tonggak pembangunan dan peningkatan kehidupan Indonesia di masa depan. Namun persoalannya, arus globalisasi yang semakin kuat menciptakan perkembangan 
teknologi dan intrusi kebiasaan atau budaya eksternal yang justru mengubah pola pikir generasi milenial. Sehingga dapat disimpulkan bahwa generasi Milenial adalah generasi yang lahir pada tahun 1980-2000. Generasi Milenial dikenal sebagai generasi yang kritis, kreatif, berpikiran terbuka, dinamis dan sangat dekat dengan media sosial.

\section{Kepemimpinan}

Kepemimpinan secara harfiah berasal dari kata pimpin yang berarti mengarahkan, mengatur, memajukan, menampilkan dan mempengaruhi. Dalam kepemimpinan terdapat prinsip tanggung jawab lahir dan batin atas keberhasilan pekerjaan atau tujuan organisasi yang akan dikelola, sehingga dalam kepemimpinan terdapat perbedaan karakter pemimpin yang menjalankan kepemimpinannya. Mengutip pendapat Miftah Thoha tentang konsep kepemimpinan adalah kegiatan mempengaruhi perilaku orang lain, juga diartikan sebagai seni mempengaruhi perilaku orang atau kelompok (Miftah Thoha, 2010:9).

Mulyasa (2004:107) memiliki pandangan yang sama bahwa kepemimpinan adalah kegiatan mempengaruhi orang untuk mencapai tujuan organisasi atau pekerjaan. Menurut Suprihatiningrum (2014: 275), kepemimpinan adalah kemampuan individu untuk memimpin, mengajak dan menggerakkan anggota untuk mengikuti setiap arah sesuai dengan apa yang ingin dicapai. Pendapat lain terkait dengan konsep kepemimpinan dikemukakan oleh Stephen P. Robbins dalam buku Badeni, yang menunjukkan bahwa kepemimpinan sebagai kemampuan hingga dari kelompok untuk mencapai tujuan mempengaruhi kemampuan yang dimaksudkan seseorang untuk mempengaruhi dalam suatu kelompok untuk mencapai tujuan.

Husaini Usman juga memberikan pengertian tentang kepemimpinan, yaitu sikap seorang pemimpin yang memerintah dan membimbing bawahannya untuk mencapai tujuan bersama (Husaini, 2014: 304). Didi Pianda (2018: 70) menunjukkan bahwa ada tiga implikasi penting dalam kepemimpinan yaitu kepemimpinan mengikutsertakan orang lain, dalam hal ini bawahannya, kemudian kepemimpinan mencakup pembagian kekuasaan yang tidak merata antara pemimpin dan anggota dan Pemimpin dapat mempengaruhi bawahannya. Konsep serupa kepemimpinan juga dipertahankan oleh Shared Goal, Hemhiel \& Coons dalam Nasrudin (2010), bahwa kepemimpinan adalah perilaku seseorang yang memimpin pelaksanaan kegiatan dan mengkoordinasikan serta memotivasi para anggota untuk mencapai tujuan yang diinginkan.

Terdapat dua gaya kepemimpinan yang dikemukakan oleh para ahli yaitu gaya kepemimpinan transformatif dan gaya kepemimpinan transaksional. Kepemimpinan transformasional adalah proses memotivasi orang lain dengan menyampaikan cita-cita moral dan nilai-nilai yang dijunjung tinggi dengan mengartikulasikan visi masa depan dan menciptakan landasan bagi kredibilitas atau kepercayaan. Sebaliknya, kepemimpinan transaksional adalah proses yang didasarkan pada standar birokrasi atau organisasi.

Berdasarkan beberapa pendapat sebelumnya, dapat disimpulkan bahwa kepemimpinan adalah sikap dan tindakan atau perilaku yang membimbing, mempengaruhi dan mendorong serangkaian individu dan kelompok untuk melakukan kegiatan untuk mencapai tujuan dan sasaran yang ditetapkan oleh organisasi atau unit pekerjaan.

\section{Spiritual Leadership}

Gaya Spiritual leadership (kepemimpinan spiritual) bukan berbicara tentang agama, namun tentang mengadopsi intisari suatu hubungan manusia dengan Sang Pencipta, Sang Ilahi, Yang Maha Kuasa, sumber kebenaran secara ruh dan jiwa, hal yang dimaksudkan pula bagaimana cara mengaplikasikannya secara universal kepada sema orang disekitar kita. Dalam hal ini, Robbins dan Judge (2008) menunjukkan bahwa 
makna spiritual di tempat kerja adalah kesadaran bahwa manusia memiliki kehidupan batin yang tumbuh dan dipupuk oleh pekerjaan bermakna yang terjadi dalam konteks komunitas. Hal yang sama juga diungkapkan oleh Conger (1994) bahwa spiritualitas adalah realisasi diri pribadi yang sebenarnya didasarkan pada kemampuan untuk mengekspresikan emosi, menggali kekuatan batin dan menggali kebenaran tentang siapa kita sebenarnya dari lubuk hati kita dan menghargai anugerah Tuhan yang agung bagi kita, maka dapat di sebut dengan pengetahuan hati.

Kepemimpinan spiritual merupakan kepemimpinan yang membawa dimensi duniawi ke dimensi spiritual (keilahian). Berdasarkan tinjauan pustaka berikut beberapa konsep Spiritual leadership (kepemimpinan spiritual) yang dikemukakan oleh para ahli. Dalam hal ini Louis W. Fry (2003) berpendapat bahwa tentang kepemimpinan spiritual merupakan pembentukan values (nilai), attitude (sikap) dan behavior (kebiasaan berperilaku) yang diperlukan untuk memotivasi diri sendiri dan orang lain secara intrinsik, sehingga keinginan kelangsungan hidup spiritual terpenuhi melalui panggilan dan keanggotaan. Lebih lanjut Fry mengungkapkan terdapat tiga ciri-ciri spiritual leadership antara lain:

a. Vision (visi), ini merupakan bagian terpenting yang menjadi dasar organisasi untuk melihat tujuan yang ingin dicapai dalam jangka pendek dan jangka panjang. Dalam hal ini, diperkuat oleh Kotter (1996: 68), visi adalah gambaran pencapaian jangka pendek dan jangka panjang dari upaya organisasi yang secara implisit (terselubung) atau eksplisit (eksplisit) untuk alasan mengapa seseorang berusaha untuk mencapainya. . . mencapai tujuan, masa depan akan datang.

b. Altruistic Love (cinta altruistik), sebuah perasaan yang utuh dalam formasi misi. Misi merupakan alasan berdirinya suatu organisasi atau perusahaan dan juga dijadikan sebagai dasar untuk membentuk suatu visi. Dalam konsep kepemimpinan, cinta altruistik dimaknai sebagai perasaan terpenuhi, sejahtera, harmonis, peduli dan menghargai diri sendiri dan orang lain, yang meliputi nilai-nilai baik hati, sabar, tidak iri, tidak mengharapkan perubahan apapun, menjadi rendah hati Mencintai, mengendalikan diri, dapat dipercaya, setia dan jujur.

c. Hope/Faith (keinginan/harapan), faith didefinisikan sebagai kepastian dari sesuatu yang diharapkan, sebagai kepastian akan sesuatu yang diharapkan, sanksi terhadap sesuatu yang tidak terlihat. Jadi kepercayaan lebih dari harapan. Ini adalah sanksi yang tidak dapat dibuktikan dengan bukti fisik. Harapan didefinisikan sebagai keinginan untuk memenuhi harapan. Seseorang yang memiliki keyakinan atau harapan harus memiliki tujuan ke arah mana dia akan pergi, kemudian tahu bagaimana mencapainya dan mampu menghadapi tantangan dan mampu menanggung penderitaan untuk mencapai tujuan yang ingin dicapai (MacArthur, 1998).

Maka, melalui intrinsic motivation yang berlandaskan ketiga ciri yaitu vision, altruistic love dan hope/faith akan tercapai keinginan spiritual survival melalui calling dan membership sehingga akhirnya peningkata kinerja karyawan yang positif dapat dicapai. Pendapat lain tentang kepemimpinan spiritual dikemukakan oleh Tobroni (2010), bahwa kepemimpinan spiritual ialah konsep kepemimpinan sejati, dimana seseorang yang memimpin dengan hati yang didasarkan pada etika religius sehingga mampu membentuk karakter, integritas dan keteladanan yang baik.

Mengutip pendapat I Gede Putu Kawiana (2019:12) Tujuan utama spiritual leadership untuk mengembangkan budaya yang mendukung kemajuan terus-menerus dan perbaikan dalam pelayanan pelanggan, melalui pemenuhan pergeseran budaya. Pemimpin berusaha membebaskan yang terbaik pada orang, dan hubungan yang terbaik untuk diri orang yang lebih tinggi serta mencari kedamaian batin bagi diri dan orang lain. Pemimpin dapat mempengaruhi upaya pengikut untuk keberhasilan dengan meningkatkan harapan pemimpin dari pengikutnya. 
SHEs: Conference Series 5 (1) (2022) 309- 317

\section{METODE}

Penelitian ini menggunakan pendekatan kepustakaan (library research), pendekatan ini dilakukan dengan cara menelaah teori, konsep dan asas yang berkaitan dengan pembahasan. Sedangkan pengumpulan data dilakukan dengan teknik studi dokumen yaitu data yang diperoleh dari Kepustakaan yang relevan. Data dianalisis dengan analisis Deskriptif Kualitatif, yang mana keseluruhan data yang terkumpul akan dianalisis secara sistematis.

\section{HASIL DAN PEMBAHASAN}

Kepemimpinan efektif yang selama ini dilakukan oleh banyak orang adalah kepemimpinan yang bermotivasi, mengembangkan potensi diri, dan membentuk hubungan yang menyatu (solid) di antara mereka. Namun, itu tidak cukup untuk mengatasi krisis psikologis, perubahan, untuk meningkatkan persyaratan kepemimpinan. Bahkan milenium, yang sebenarnya berkembang seiring kemajuan teknologi, di mana semua bidang berubah, membutuhkan kepemimpinan yang disertai dengan landasan spiritual, moral dan agama yang menjalin hubungan intrinsik dengan Sang Pencipta, generasi milenial yang selama ini dianggap lebih mengedepankan hawa nafsu, ego dan keinginan dengan mengambil segala hal yang diinginkannya secara instan dan cepat yang karena didukung perkembangan teknologi.

Seperti Kaifi dkk (2012), mengungkapkan bahwa diperkirakan generasi milenial akan mulai mengambil alih tempat kerja, teknologi yang lebih terintegrasi yang mana dalam proses kerja generasi milenial dikenal sebagai fokus pencapaian. Kaifi lebih lanjut menjelaskan bahwa, generasi milenial mempunyai kebutuhan yang tidak hanya harus berkinerja baik, tetapi ingin unggul dan melampaui semua tujuan dan aspirasi dengan menikmati memanfaatkan teknologi. Maka, diperlukannya gaya kepememimpinan yang dapat membantu generasi milenial menjadi pemimpin yang handal dan memaknai kehidupan bekerja dengan utuh, dalam hal ini spiritual leadership menjadi gaya yang perlu di kembangkan didalam individu era milenial agar mampu memanfaatkan teknologi tanpa mengesampingkan tujuan bersama sebagai manusia yang berke-Tuhanan.

Membangun jiwa kepemimpinan dengan model spiritual leadership di era milenial sangat penting untuk terapkan, sebagaimana penelitian yang dilakukan oleh Ema Bilda Fortuna (2020), yang berjudul pentingnya kepemimpinan spiritual terhadap kinerja karyawan. Dalam penelitiannya, didapatkan hasil bahwa kepemimpinan spiritual berdampak pada kinerja karyawan di perusahaan. Melalui kepemimpinan spiritual, seorang pemimpin dapat membimbing karyawan melalui nilai-nilai spiritual yang membentuk nilai, etika dan lingkungan kerja yang baik. Jani Y. Rondonuwu, W.A. Areros dan Sofia A. P. Sambu (2017) yang berjudul pengaruh Kepemimpinan Spiritual terhadap kinerja karyawan kapda PT. Ciputra International Proyek City of Blessing Citraland Manado. Hasil penelitian menunjukkan bahwa pengaruh bimbingan spiritual terhadap kinerja sangat kuat dan penting untuk selalu diterapkan, hal ini menjadi masukan bersama yang diperlukan untuk memperkuat nilai kepemimpinan spiritual dalam kinerja karyawan, karena kedepannya seorang perusahaan akan memberikan hasil yang positif. Sangat perlu menerapkan tuntunan spiritual, oleh karena itu diperlukan inovasi melalui gaya kepemimpinan.

Kepemimpinan spiritual juga dikenal sebagai sebagai kepemimpinan berdasarkan etika agama. Kepemimpinan yang dapat menginspirasi, membangkitkan, mempengaruhi dan menggerakkan melalui keteladanan, pelayanan, kasih sayang dan penerapan nilai-nilai ketuhanan serta atribut lainnya dalam tujuan proses budaya dan perilaku kepemimpinan. Bimbingan spiritual meliputi keteladanan pelayanan, integritas, cinta kasih dan nilai-nilai ketuhanan dalam tujuan, proses, budaya, dan sikap yang 
sangat dibutuhkan di era milenial untuk menjawab tantangan teknologi (Hendricks dan Ludeman, 1996:96)

a. Keteladanan, artinya menjadi keteladanan sebenarnya adalah energi positif, yang menjadi poin utama kepemimpinan. Perilaku seorang manajer dapat dilihat secara keteladanan melalui bukti nyata perilaku manajerial dalam kehidupan sehari-hari, tidak hanya melalui janji-janji atau pernyataan-pernyataan sederhana. Secara keteladanan, seseorang dapat mengenali, melihat dan meneladani antara lain kedisiplinan, keadilan, kerjasama, kejujuran dan panutan untuk memotivasi karyawan atau anggota.

b. Integritas, dibangun dari diri sendiri, sejak sekarang dan harus konsisten, ketika suatu saat kita menjadi pemimpin maka integritas yang baik bisa kita rasakan dalam kehidupan kita. Orang yang berintegritas memberikan diri demi kepentingan orang lain, bukan diri sendiri. Kita harus membentuk diri kita dan mampu menguasai diri kita sendiri, harus memiliki self-control. Pemimpin yang berintegritas memimpin dengan bijaksana, cinta, dan berani. Pemimpin yang selalu disinari oleh kebajikan Tuhan. Pemimpin yang tidak pernah merasakan takut karena dia tau bahwa dirinya tidak salah, penuh kebijaksanaan dan cinta kasih. Mampu menerapkan sebuah manajemen dengan benar dan yang memberi nilai baik terhadap karyawannya yang dimana mampu menghadapi kondisi masalah kerja dan yang nantinya juga akan menjadikan seorang bawahan yang berkualitas, berkuantitas, dan mempunyai nilai positif dalam dunia kerja. Ini semua dapat tercapai jika lewat kepemimpinan berkualitas dan taat terhadap Sang Pencipta.

c. Kasih, merupakan perasaan yang dimiliki oleh setiap orang, dimana perasaan ini akan muncul apabila sesorang tersebut memiliki rasa penyayang. Adanya rasa kasih menjadikan manusia memiliki keterkaitan antar tujuan hidup yang diperjuangkan. Sebagai seorang pemimpin memiliki kasih akan selalu memberikan yang terbaik antar hubungan dengan Tuhan, manusia, alam dan makhluk hidup lainnya di dunia.

d. Memiliki nilai ke-Tuhanan dalam tujuan, proses, budaya dan sikap dalam kepemimpinan. Artinya, nilai-nilai kebaikan yang diajarkan disetiap bidang kepercayaan dalam hal ini ialah agama menjadi landasan utama dalam mewujudkan tujuan hidup, menjalankan proses kehidupan, memiliki kebiasaan dalam berbudaya baik serta sikap kepemimpinan yang diterapkan berlandaskan ke-Tuhanan dalam bersikap kepada sesama manusia.

\section{SIMPULAN}

Berdasarkan dari hasil penelitian ini dapat diambil kesimpulan bahwa kepemimpinan efektif selama ini yang telah dilakukan oleh banyak orang merupakan kepemimpinan yang bersifat motivasi, pengembangan potensi diri, serta membentuk suatu kerjasama yang menyatu (solid). Namun, hal tersebut tidaklah cukup dalam mengelola krisis mental, perubahan-perubahan, melakukan suatu pertumbuhan dalam tuntutan kepemimpinan. Bahkan diera milenial yang sejatinya merupakan era yang berkembang berdampingan dengan kemajuan teknologi yang disegala bidang berubah, maka diperlukannya dalam kepemimpina disertai landasan spiritual, moral dan agama yang memiliki hubungan intrinsik dengan sang Pencipta. Untuk memberikan suatu upayadi Era Milenial dalam hal kepemimpinan dengan menanamkan nilai-nilai Spiritual Leadership haruslah dengan cara berbagai hal tentunya dengan cara membangun jiwa kepemimpinan di berbasis Spiritual Leadership. Karena, Spiritual Leadership mengandung keteladanan, pelayanan, integritas, kasih, serta nilai ke-Tuhanan dalam tujuan, proses, budaya dan sikap yang sangat dibutuhkan di Era Milenial dalam menjawab tantangan teknologi dan perkembangna zaman. 


\section{DAFTAR PUSTAKA}

Agung, Lilik AM. (2009). Spiritual Leadership. Jakarta: Gagas Bisnis

Ashmos. D., \& Duchon, D. (2000). "Spirituality at Work: a Conceptualization and Measure", Journal of Management Inquiry, 9(2), 134-145

Conger JA, Kanungo RN. (1994). "Charismatic leadership in organizations: Perceived behavioral attributes and their measurement", Journal of Organizational Behavior, 15: 439-452

Erkutlu, Hakan. (2011). "The Moderating Role of Organizational Culture in The Relationship Between Organizatinal Justice and Organizational Citizenship Behaviors", Leadership \& Organization Development Jornal, 32 (6), 532- 554

Fairholm, G. W. (1998). Perspectives on Leadership: From the Science of Management to its Spiritual Heart. Westport: CT: Praeger

Fortuna, Ema Bilda. (2020). "Pentingnya Kepemimpinan Spiritual terhadap Kinerja Karyawan", Journal of Education Psychology and Counseling, 2(1) 14-18

Fry, Louis W. (2003). "Toward a Theory of Spiritual Leadership", The Leadership Quarterly, no. 14: 693-727

Gay Hendricks \& Kate Ludeman. (1996). The Corporate Mystic: A Guidebook for Visionaries with Their Feet on the Ground. New York: Bantam Book

Kaifi, B. A., Nafei, W. A., Khanfar, N. M., \& Kaifi, M. M. (2012). "A Multi-Generational Workforce: Managing and Understanding Millennial, Internasional Journal of Business and Management, 7(24), 88-93.

Kawiana, I Gede Putu. (2019). Spiritual Leadership: Membangun Kinerja Organiasi. Denpasar: UNHI Press

Kotter, J. P. (1996). Leading Change. Boston: Harvard Business School Press

Lancaster, L. C., \& Stillman, D. (2002). When Generations Collide: Who They Are. Why They Clash How to Solve the Generational Puzzle at Work. New York: HarperCollins

MacArthur, J. F. (1998). In the Footsteps of Faith. Wheaton, IL: Crossway Books

Mansyur, Ahmad Yasser. (2013). "Personal Prophetic Leadership sebagai Model Pendiidkan Karakter Intrinsik atasi Korupsi, Jurnal Pendidikan Karakter: Tahun III Nomor 1

Marcom, Mix. (2018). Millennials. Jakarta: Fantasious x Loveable

Mulyasa, E. (2004). Kurikulum Berbasis Kompetensi: Konsep Karakteristik dan I mplementasi. Bandung: Rodya Karya

Pianda, Didi. (2018). Kinerja Guru: Kompetensi Guru, Motivasi Kerja, Kepemimpinan Kepala Sekolah. Jawa Barat: CV. Jejak

Pratiwi, Inge, P. Helen Widjaja \& Christina Catur Widayanti. (2018). "Pengaruh Gaya Kepemimpinan Participative Terhadap Prestasi Kerja Dan Kinerja Karyawan pada PT Hero Supermarket Tbk. Bintaro Divisi Sales Support", Journal Ekonomi akultas Ekonomi dan Bisnis Universitas Mercu Buana, Fakultas Ekonomi Universitas Tarumanagara, 23(1) 76-98

Robbins, Stephen P \& Judge, Timothy A. (2008). Organizational Behavior. New Jersey: Pearson Educat

Rondonuwu, Jani Y, William A. Areros \& Sofia A. P. Sambul. (2017). "Pengaruh Kepemimpinan Spiritual Terhadap Kinerja Karyawan Pada PT. Ciputra International Proyek City of Blessing Citraland Manado", Jurnal Administrasi Bisnis UNSRAT, 5(6)

Suprihatiningrum, Jamil. (2014). Strategi Pembelajaran. Yogyakarta: Ar-Ruzz Media Tobroni. (2010). The Spiritual Leadership (Pengefektifan Organisasi Noble Industry melalui Prinsip-prinsip Spiritual). Cet 2. Malang: UMM Press

Thoha, Miftah. (2010). Kepemimpinan Dalam Manajemen. Jakarta: PT. Raja Grafindo Persada 
Usman, Husaini. (2014). Manajemen: Teori, Praktek dan Riset Pendidikan. Jakarta: Bumi Aksara

Warrilow, Stephen. (2009). Transformational Leadership Theory-The 4th Key Components in Leading Change \& Managin Change. Akses (online) https://ezinearticles.com/?Transformational-Leadership-Theory---The-4KeyComponents-in-Leading-Change-and-Managing\%20Change\&id=27552. Diakses pada 26 September 2021, pukul 14.33 WIB

Widjaja, Muhammad Yusuf Aria. (2020). "Konsep Spiritual Leadership Menghidupkan Sunnah Harian Nabi Muhammad dalam Pembentukan Karakter SDI di Era Millenial", Jurnal Perbankan Syariah dan Ekonomi Syariah, 2(1), 69-84 Yuswohady. (2016). Millennial Trends 2016.

Akses (online) http://www.yuswohady.com/2016/01/17/millennial-trends-2016/. Pada 25 September 2021 